\title{
Photobiomodulation (PBMT) and Antimicrobial Photodynamic Therapy (aPDT) In Oral Manifestations of Patients Infected by SARS-CoV-2: Systematic Review and Meta-Analysis
}

Juliano Abreu Pacheco ( $\sim$ japacheco@usp.br )

USP: Universidade de Sao Paulo https://orcid.org/0000-0002-5964-1887

Kelly Fernanda Molena

USP: Universidade de Sao Paulo

Camila Raíssa Oliveira Gontijo Martins

USP: Universidade de Sao Paulo

Silmara Aparecida Milori Corona

USP: Universidade de Sao Paulo

Maria Cristina Borsatto

USP: Universidade de Sao Paulo

\section{Research Article}

Keywords: Photodynamic Therapy, Low Level Light Therapy, LLLT, Covid-19, Oral Manifestation, Coronavirus, Sars-Cov-2

Posted Date: June 28th, 2021

DOl: https://doi.org/10.21203/rs.3.rs-664972/v1

License: (c) (i) This work is licensed under a Creative Commons Attribution 4.0 International License.

Read Full License 


\section{PHOTOBIOMODULATION (PBMT) AND ANTIMICROBIAL PHOTODYNAMIC THERAPY (APDT) IN ORAL MANIFESTATIONS OF PATIENTS INFECTED BY SARS-COV-2: SYSTEMATIC REVIEW AND META-ANALYSIS}

Ms Juliano Abreu Pacheco ${ }^{1}$, Ms Kelly Fernanda Molena ${ }^{2}$, Ms Camila Raíssa Oliveira Gontijo Martins $^{3}$, Phd Silmara Aparecida Milori Corona ${ }^{4}$, Phd Maria Cristina Borsatto 5

${ }^{1}$ Dental Surgeon, Doctoral student at EERP / USP Ribeirão Preto, Master in Intensive Care from Unibrati (SP), Qualified in Hospital Dentistry at Hospital Israelita Albert Einstein (SP), Research Coordinator at Ribeirão Preto Cancer Hospital,

${ }^{2}$ Dental Surgeon, Doctoral student in the Postgraduate Program in Pediatric dentistry at the School of Dentistry of Ribeirão Preto - University of São Paulo, Ribeirão Preto, Brazil;

${ }^{3}$ Dental Surgeon, Doctoral student in the Postgraduate Program in Pediatric dentistry at the School of Dentistry of Ribeirão Preto - University of São Paulo, Ribeirão Preto, Brazil, Master in Integrated dental clinic (Federal University of Uberlandia/MG);

${ }^{4}$ Department of Restorative Dentistry, School of Dentistry of Ribeirão Preto, University of São Paulo, São Paulo, Brazil;

${ }^{5}$ Department of Pediatric Dentistry, School of Dentistry of Ribeirão Preto, University of São Paulo, São Paulo, Brazil.

\section{Correspondence}

Juliano Abreu Pacheco'

R. Otávio Martins Braga, 50 - Res. Florida, Ribeirão Preto - SP, 14026-270

Email: japacheco@usp.br 


\section{ABSTRACT}

Introduction: In 2019, a viral and respiratory pathology called COVID-19 emerged in Wuhan, China and spread to other continents. Its main symptoms include fever, cough, dyspnea, myalgia, anorexia and respiratory distress in the most severe cases, which can lead to death. Furthermore, manifestations in the oral cavity such as ageusia and dysgeusia, as well as lesions in other regions of the oral cavity, can be observed. Objective: Are Photobiomodulation (PBM) and Antimicrobial Photodynamic Therapy (aPDT) effective to treat oral manifestations of patients infected with SARS-CoV-2? Methodology: It was defined following the PRISMA guidelines (Preferred Report on Systematic Reviews and Meta-Analysis), and registered in the database in the International Prospective Registry of Systematic Reviews (PROSPERO), including articles published between December 2019 to May 2021, Independent reviewers selected studies, qualitatively extracted data, assessed risk of bias using the Joanna Briggs Institute, assessed certainty of evidence through metaanalysis. Results: Of the 5,959 articles found, 32 fit the types of studies, but only 5 of them attended the pre-established criteria. Data corresponding to the articles, protocols used and clinical outcome were extracted, then submitted to qualitative and descriptive analysis. The results show favoring the associated use of PBMT with aPDT ( $p=0.004)$, and the isolated use of PBMT with the result of significant " $p=0.005$ " and good confidence interval $(7.18,39.20)$ in ulcerative lesions, herpetic, aphthous, erythematous, petechiae and necrotic areas. Conclusion: According to the articles included in this review, PBMT and aPDT were effective in the treatment of oral lesions of patients infected with COVID-19 in a short period of time.

Keywords: Photodynamic Therapy; Low Level Light Therapy; LLLT; Covid-19; Oral Manifestation; Coronavirus, Sars-Cov-2 


\section{INTRODUCTION}

In the last quarter of 2019 in the city of Wuhan, Hubei province in China, the viral and respiratory pathology called coronavirus (COVID-19) spread to other continents, reaching all countries, according to publicity by the World Health Organization. The name of the acronym Covid-19 came to replace the provisional name "2019-nCoV", ${ }^{1}$ shortly after the onset of respiratory disease. The new name was chosen because it is easy to pronounce and does not have a stigmatizing reference to a particular country or population. This acronym stands for, "Co" stands for corona, "vi" stands for virus, and "d" stands for "disease". The number 19 indicates the year of its appearance, 2019. Currently, according to data from the Johns Hopkins University, the new coronavirus has infected more than 134 million people worldwide and the death toll has surpassed 2.7 million. Due to the rapid spread of the disease and the increasing rates of hospitalizations and mortality, the new COVID-19 pandemic has become a global emergency and public health challenge. ${ }^{2}$

COVID-19 is an acute respiratory pathology and the set of signs and symptoms develop rapidly in a synchronous and varied manner, leading to a global characterization of the name "Severe Acute Respiratory Syndrome Coronavirus 2" (SARS-COV-2). The most common symptoms are fever, dyspnea, cough, myalgia and anorexia. ${ }^{3}$ In severe cases, pulmonary impairment occurs with increased respiratory rate ( $>30$ times / min.), decreased $\mathrm{O}_{2}$ saturation (<93\% in room air) and $\mathrm{PaO}_{2} / \mathrm{FiO}_{2}(<300 \mathrm{~mm} \mathrm{Hg})$ are observed ${ }^{4}$ Critical cases include severe acute respiratory syndrome, RNAmy, acute cardiac injury, and multiple organ failure. ${ }^{5}$

Due to this new pandemic context, and the growing expansion of the number of cases, it is possible to identify and relate a wide variety of signs and symptoms in these patients contaminated by the coronavirus with the appearance of secondary lesions in the oral cavity.

There are still no estimates of the percentage of patients with COVID-19 who present oral lesions, since the data found in the literature are limited to a few case reports. ${ }^{6}$ However, there are reports of oral manifestations by clinicians and researchers related to various comorbidities such as ulcer, erosion, blister, vesicle, pustule, fissured or depapillary tongue, macula, papule, plaque, pigmentation, halitosis, whitish areas, hemorrhagic crust, necrosis, petechiae, swelling, erythema and spontaneous bleeding. The most affected sites were tongue (38\%), lip mucosa (26\%) and palate $(22 \%){ }^{7}$ Suggested diagnoses of lesions 
are diverse, including aphthous stomatitis, herpetic lesions, candidiasis, vasculitis, Kawasaki type, eruption by drug, periodontal necrotizing disease, bullous angina type, angular cheilitis, atypical Sweet's syndrome and Melkerson-Rosenthal syndrome. Oral lesions are characterized as symptomatic in $68 \%$ of cases and similar in both sexes $(49 \%$ female and $51 \%$ male). And it should be noted that the lack of oral cavity hygiene, opportunistic infections, stress, immunosuppression, vasculitis and inflammatory response secondary to COVID-19 are being characterized as the most important causal factors for the appearance of these lesions in patients with COVID-19.7

Taste disorder (dysgeusia) is the most common oral manifestation found in this niche of patients with SARS-COV-2. In mild cases, oral mucosal lesions evolve before or simultaneously with the initial respiratory symptoms; however, in patients who worsened and required medication and hospitalization, oral lesions had an evolution process approximately between 7 to 24 days after the onset of symptoms. ${ }^{8}$

There are physiological structures in the oral cavity available through cell receptors called Angiotensin-Converting Enzyme 2 (ACE2)..$^{9}$ The coronavirus has in its structure the glycoprotein S, which is the key factor for the entry of SARS-CoV-2 into the cell, which contains two functional domains: $\mathrm{S} 1$ which is an angiotensin converting enzyme receptor binding domain 2 (ACE2) and the $S 2$ which is required for coronavirus fusion and cell membranes. There is a resonance in global studies that ACE2 is likely the receptor for SARSCoV-2 which could induce an increase in the susceptibility and/or progression of COVID-19 disease, and this severity would be closely linked to increased viral load in the oropharyngeal region with eventual systemic repercussions for respiratory epithelial cells. ${ }^{10,11}$

In the event of minimizing these secondary manifestations caused by Covid-19, Low Intensity Laser Therapy (LLLT) emerges as a practical tool and is characterized by its non-invasiveness to biological tissues, which through a wavelength (red or infrared) stimulates responses to injured tissue by promoting anti-inflammatory, analgesic and healing effects. LLLT promotes the effect of Photobiomodulation (PBMT) which is able to regulate antioxidant defenses and reduce oxidative stress. ${ }^{12}$

PBMT is based on the interaction of light with biological tissues, stimulating photophysical, chemical and biological events in the cell, in the search for better therapeutic responses, consequently altering cell metabolism. It is known that this therapy can currently biostimulate or bioinhibit cells depending on different variables relevant to light. The 
therapeutic effects of low-power laser irradiation have been investigated in several health areas. Some beneficial effects such as improved immunosuppression-immunostimulation, stabilization of autoimmune disease and nerve regeneration have been reported in the literature. ${ }^{13}$

The basic physiological effects and mechanisms of PBMT are widely discussed in the world literature, and have excellent results in healing processes, decontamination, biomodulation of the inflammatory process, and pain control. Indications for clinical applications of PBMT at the cellular level are broad within the healthcare field, and include interdisciplinary therapies that involve the treatment of different pathologies, as well as pain control in general.

It should be noted that the imbalance of the oral cavity microbiota may provide the functional instability of the oropharynx with the development of numerous secondary pathogens related to systemic diseases. This instability open space for colonization by microorganisms in other organs that may evolve into an undesirable effect as they produce potent toxic agents. The oral microbiome in patients with COVID-19 has a greater bacterial sensitivity and specificity due to the vulnerability of the immune system. In this context, PBMT proposes another interesting aspect for the decontamination of the oral microbiota in these patients, given that the biosensors contained in the oral region through photodynamic therapy will activate a photosensitizing substance by a red laser with a high efficiency in the decontamination of microorganisms, such as bacteria, viruses and fungi. We call this process Antimicrobial Photodynamic Therapy (aPDT). ${ }^{14}$

The aPDT has photosensitization as a mechanism, which consists of the direct action of light with a photosensitizing agent together with oxygen. This process induces the production of free radicals that promote microbial lysis, promoting decontamination. ${ }^{15}$ This therapy is of low cost, basically without side effects, and the possibility of controlling the oral microbiota.

When a photosensitizing substance, such as methylene blue, for example, is photoactivated in the presence of oxygen, it leads to the generation of reactive oxygen species (ROS), causing irreversible damage to target structures such as proteins and lipids, leading to death of microorganisms by apoptosis or necrosis. ${ }^{16}$ In viral infectious agents, aPDT can affect the lipid or protein structures of the viral envelope membrane, even the 
nucleic acid, regardless of the specific interaction with a receptor, indicating that it is an efficient tool to eliminate these infectious agents. ${ }^{17,18}$

The aim of this manuscript is to present a systematic review of the literature on the use of PBMT and aPDT in oral lesions of patients affected by COVID-19, reviewing all relevant observational studies to answer the following question: Photobiomodulation (PBMT) and antimicrobial Photodynamic Therapy (aPDT) are effective to treat oral manifestations of patients infected with SARS-CoV-2?

\section{MATERIAL AND METHODS}

The methodology was defined following the PRISMA guidelines (Preferred Systematic Reviews and Meta-Analysis Report) ${ }^{19}$, and registered in the database in the International Prospective Registry of Systematic Reviews (PROSPERO) under registration CRD42021250106.

The literature search was conducted in 4 databases and in gray literature, whose question focused in the review was "Photobiomodulation (PBMT) and antimicrobial Photodynamic Therapy (aPDT) are effective to treat oral manifestations of patients infected by SARS-CoV-2?". The flow diagram was used as the strategy design in this study.

\subsection{Literature research}

A search was performed in the PubMed, Medline, CINAHL, Google Scholar databases, as well as a manual search of the reference lists of the included studies, from January 1, 2019 to May 23, 2021. The first phase established an investigation for define $\mathrm{MeSH}$ (Medical Subject Headings) terms to ensure high sensitivity and accuracy, and researchers tracked abstract and publication titles. The MESH terms used in searches across all databases were "COVID 19" or "SARS-COV-2" or "Coronavirus infections" or coronavirus and "Photodynamic therapies" or "Photodynamic therapy" or "PDT methylene blue" or "Cold laser decontamination" or" Photodynamic LLLT "or Photobiomodulation and" Oral manifestations "or" Oral injury "and" Angiotensin II "or" ACE2 "or" ECA2 ".

\subsection{Election criteria}

Articles describing Photobiomodulation Therapy and Antimicrobial Photodynamic Therapy as treatment for oral manifestations in patients infected with COVID-19, based on titles and abstract, were included in this review. Original articles in English, Spanish and 
Portuguese within the defined period (2019-2021) with abstract available in the database were evaluated and validated within the inclusion criteria. Inclusion criteria were defined using the PECOS strategy (Population, Exposure, Comparator, Outcomes and Study Design) (Table 1) and consisted of "in vivo" studies and case reports, excluding works published as letters to the editor, systematic reviews and articles not available in full.

Table 1. PECOS Strategy and inclusion criteria using on research

\begin{tabular}{ll}
\hline Population & $\begin{array}{l}\text { Patients infected with COVID-19 who had oral lesions and were } \\
\text { treated with PBMT or aPDT laser therapy }\end{array}$ \\
Exposure & $\begin{array}{l}\text { Patients were exposed to Photobiomodulation Therapy (PBMT) } \\
\text { and/or Antimicrobial Photodynamic Therapy (aPDT) } \\
\text { Comparison between patients who did not use PBMT and/or } \\
\text { aPDT }\end{array}$ \\
\hline Obomparator \\
Outer using PBMT and aPDT \\
atcomes
\end{tabular}

\subsection{Selection and quality assessment of relevant studies}

Articles selected according to the selection criteria were retrieved in PDF format, numbered and randomly distributed among three researchers. The reference list was manually checked by the researchers in order to retrieve publications that were not previously found in the database search, to increase the sensitivity and quality of the review. A consensus meeting was held to discuss divergences after evaluating the quality of publications and guaranteeing the validation of the articles selected by the researchers.

\subsection{Data Extraction}

Articles included in the study were randomly distributed among researchers to collect relevant data.

Through a table, important data were selected, including: author and year of publication, local and type of lesion, applied technique and parameter of laser and outcome, whether there was improvement of the lesion, in how many days there was improvement, whether the type of light source interfered and to observe whether these complementary therapies would be effective or not in the treatment of oral lesions in patients affected by COVID -19. With the results collected, the data were evaluated one by one, each case addressed in the literature was presented in each row of the table. 


\subsection{Bias risk}

Quality and risk of bias in selected articles were independently performed by two authors (MARTINS and MOLENA), using the Joanna Briggs Institute's Critical Assessment Checklist for systematic reviews and research summaries. ${ }^{20}$ The third author (PACHECO) was consulted in case of disagreement. Scoring decisions were discussed by all reviewers prior to assessments. Checklists allow for the quantification of scores, where high scores represent a low risk of bias; low scores indicate a high risk of bias or "unclear" domains in publications.

\section{RESULTS}

\subsection{Selection and heterogeneity of studies}

In the first phase, 5,959 articles were identified in the databases and, after removing the duplicates, 1,650 articles remained for reading the title and abstract. After evaluating all records, 32 articles were selected where they were read in full and following the inclusion and exclusion criteria, 5 articles were finally included, as instructed in the Infographic (Infog.01).

Infographic 01. Literature search flow diagram and selection criteria adapted from PRISMA (Preferred report items for systematic reviews and meta-analysis).

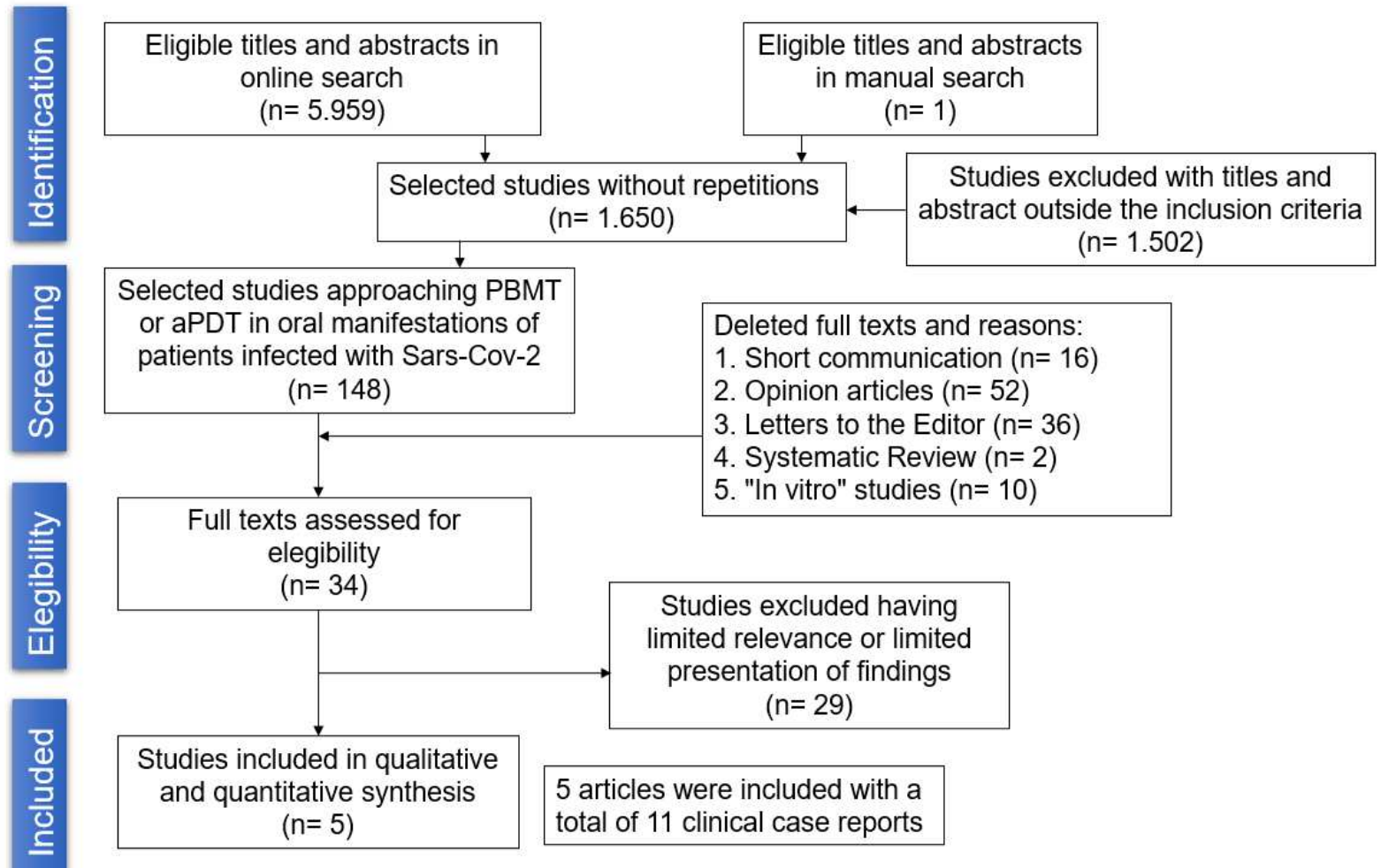


All studies were carried out in Brazil, they were case reports in the literature and were published between January and May 2021, in English, where patients were admitted to hospitals with symptoms characteristic of COVID-19 and later confirmed through the examination RT-PCR. However, they used different therapeutic approaches for lesions in the oral cavity, including PBMT, 21, 22 PBMT associated with aPDT ${ }^{23,24}$ and awaiting spontaneous regression of the lesions without any laser intervention. ${ }^{21,} 22$ Thus, 5 articles found in the literature presented a total of 11 cases using PBMT and aPDT as therapeutic strategies for the regression of oral lesions and painful symptoms in patients with COVID-19 (Tab 02).

Of these, 3 were male (27\%) and 8 female (73\%), where 8 patients were aged over 60 years (mean 75 years) and 3 were younger than 60 years (mean 47 years).

The place most affected by the lesions were upper and lower lip (33.3\%), followed by tongue (12.5\%), hard palate (8.3\%), buccal mucosa (4.1\%) and attached gingiva $(4,1 \%)$.

Among the most frequent types of lesions are ulcers (50\%), herpetic lesions (40\%), in addition to the rest being expressed by necrotic, erythematous, vesicular and petechiae areas.

\begin{tabular}{|c|c|c|c|}
\hline Author and Year & Local and type of lesion & Technique applied and Laser parameter & Outcome \\
\hline $\begin{array}{l}\text { Brandão et. al., } \\
2021\end{array}$ & $\begin{array}{l}\text { Upper lip, lower lip and anterior } \\
\text { dorsum of tongue. Necrotic and } \\
\text { aphthous ulcers }\end{array}$ & $\begin{array}{l}\text { PBMT. } 40 \mathrm{~mW} \text {, beam area } 0.04 \mathrm{~cm}^{2}, 1 \mathrm{~W} / \\
\mathrm{cm} 2 \text { irradiance, energy } 0.4 \mathrm{~J} \text { and } 10 \mathrm{~J} / \mathrm{cm}^{2} \\
\text { creep and } 660 \mathrm{~nm} \text {. }\end{array}$ & $\begin{array}{l}\text { Symptom relief within } 2 \\
\text { days and complete } \\
\text { resolution of lesions } \\
\text { within } 11 \text { days }\end{array}$ \\
\hline $\begin{array}{l}\text { Brandão et. al., } \\
2021\end{array}$ & $\begin{array}{l}\text { Upper lip, lower lip and anterior } \\
\text { dorsum of tongue. Necrotic areas } \\
\text { and aphthous ulcers }\end{array}$ & $\begin{array}{l}\text { PBMT. } 40 \mathrm{~mW} \text {, beam area } 0.04 \mathrm{~cm}^{2}, 1 \mathrm{~W} / \\
\mathrm{cm} 2 \text { irradiance, energy } 0.4 \mathrm{~J} \text { and } 10 \mathrm{~J} / \mathrm{cm}^{2} \\
\text { creep and } 660 \mathrm{~nm} \text {. }\end{array}$ & $\begin{array}{l}\text { Improvement of intraoral } \\
\text { lesions in } 10 \text { days and lip } \\
\text { ulcerations there was no } \\
\text { improvement until the } \\
\text { publication of the case, } \\
\text { as well as the clinical } \\
\text { case of the patient. }\end{array}$ \\
\hline $\begin{array}{l}\text { Brandão et. al., } \\
2021\end{array}$ & $\begin{array}{l}\text { Lateral edge of tongue and palate. } \\
\text { Petechiae and necrotic areas }\end{array}$ & $\begin{array}{l}\text { PBMT. } 40 \mathrm{~mW} \text {, beam area } 0.04 \mathrm{~cm}^{2}, 1 \mathrm{~W} / \\
\mathrm{cm} 2 \text { irradiance, energy } 0.4 \mathrm{~J} \text { and } 10 \mathrm{~J} / \mathrm{cm}^{2} \\
\text { creep and } 660 \mathrm{~nm} \text {. }\end{array}$ & $\begin{array}{l}\text { Total pain control in } 5 \\
\text { days }\end{array}$ \\
\hline $\begin{array}{l}\text { Brandão et. al., } \\
2021\end{array}$ & $\begin{array}{l}\text { Upper and lower lip mucosa. } \\
\text { Necrotic and hemorrhagic ulcers. }\end{array}$ & $\begin{array}{l}\text { PBMT. } 40 \mathrm{~mW} \text {, beam area } 0.04 \mathrm{~cm}^{2}, 1 \mathrm{~W} / \\
\mathrm{cm} 2 \text { irradiance, energy } 0.4 \mathrm{~J} \text { and } 10 \mathrm{~J} / \mathrm{cm}^{2} \\
\text { creep and } 660 \mathrm{~nm} \text {. }\end{array}$ & $\begin{array}{l}\text { Pain regression and } \\
\text { clinical improvement in } 7 \\
\text { days }\end{array}$ \\
\hline Teixeira et. al., 2021 & $\begin{array}{l}\text { Upper and lower lip injury. } \\
\text { Hemorrhagic and necrotic ulcers }\end{array}$ & $\begin{array}{l}\text { PBMT and aPDT. } 100 \mathrm{~mW}, 33 \mathrm{~J} / \mathrm{cm}^{2}, 0.5 \mathrm{~J} \\
\text { and } 5 \mathrm{~s} \text { per point. A total of } 6 \text { points were } \\
\text { distributed for the injuries. Soon after, an } \\
\text { aPDT technique was performed, with } 0.01 \% \\
\text { methylene blue applied to all lesions, and } \\
\text { after } 3 \text { min (pre-irradiation time), the same } \\
\text { laser parameters were used, but providing } 40 \\
\mathrm{~s}(4 \mathrm{~J}) \text { per lesion, } 660 \mathrm{~nm} \text {. }\end{array}$ & $\begin{array}{l}\text { Total improvement of the } \\
\text { lesion in } 3 \text { days and } \\
\text { healing within the first } 24 \\
\text { hours. }\end{array}$ \\
\hline Teixeira et. al., 2021 & $\begin{array}{l}\text { Upper and lower lip injury. } \\
\text { Erythematous lesions. }\end{array}$ & $\begin{array}{l}\text { PBMT and aPDT. } 100 \mathrm{~mW}, 33 \mathrm{~J} / \mathrm{cm}^{2}, 0.5 \mathrm{~J} \\
\text { and } 5 \mathrm{~s} \text { per point. A total of } 6 \text { points were } \\
\text { distributed for the injuries. Soon after, an } \\
\text { aPDT technique was performed, with } 0.01 \% \\
\text { methylene blue applied to all lesions, and } \\
\text { after } 3 \text { min (pre-irradiation time), the same } \\
\text { laser parameters were used, but providing } 40 \\
\mathrm{~s}(4 \mathrm{~J}) \text { per lesion, } 660 \mathrm{~nm} \text {. }\end{array}$ & $\begin{array}{l}\text { Total improvement of the } \\
\text { lesion after } 24 \text { hours }\end{array}$ \\
\hline Teixeira et. al., 2021 & $\begin{array}{l}\text { Upper and lower lip injury. Painful } \\
\text { scaly lip lesions. }\end{array}$ & $\begin{array}{l}\text { PBMT and aPDT. } 100 \mathrm{~mW}, 33 \mathrm{~J} / \mathrm{cm}^{2}, 0.5 \mathrm{~J} \\
\text { and } 5 \mathrm{~s} \text { per point. A total of } 6 \text { points were } \\
\text { distributed for the injuries. Soon after, an }\end{array}$ & $\begin{array}{l}\text { Total improvement of } \\
\text { lesions in } 3 \text { days. }\end{array}$ \\
\hline
\end{tabular}




\begin{tabular}{|c|c|c|c|}
\hline & & $\begin{array}{l}\text { aPDT technique was performed, with } 0.01 \% \\
\text { methylene blue applied to all lesions, and } \\
\text { after } 3 \text { min (pre-irradiation time), the same } \\
\text { laser parameters were used, but providing } 40 \\
\mathrm{~s}(4 \mathrm{~J}) \text { per lesion, } 660 \mathrm{~nm} \text {. }\end{array}$ & \\
\hline Teixeira et. al., 2021 & $\begin{array}{l}\text { Upper and lower lip injury. Painful } \\
\text { scaly lip lesions. }\end{array}$ & $\begin{array}{l}\text { PBMT and aPDT. } 100 \mathrm{~mW}, 33 \mathrm{~J} / \mathrm{cm}^{2}, 0.5 \mathrm{~J} \\
\text { and } 5 \mathrm{~s} \text { per point. A total of } 6 \text { points were } \\
\text { distributed for the injuries. Soon after, an } \\
\text { aPDT technique was performed, with } 0.01 \% \\
\text { methylene blue applied to all lesions, and } \\
\text { after } 3 \text { min (pre-irradiation time), the same } \\
\text { laser parameters were used, but providing } 40 \\
\mathrm{~s}(4 \mathrm{~J}) \text { per lesion, } 660 \mathrm{~nm} \text {. }\end{array}$ & $\begin{array}{l}\text { Complete resolution of } \\
\text { lesions within } 4 \text { days }\end{array}$ \\
\hline $\begin{array}{l}\text { Ramires et. al., } \\
2021\end{array}$ & $\begin{array}{l}\text { Upper and lower lip injury. } \\
\text { Extensive necrotic ulcers. }\end{array}$ & $\begin{array}{l}\text { PBMT and aPDT. aPDT was performed for } 2 \\
\text { days. For this, } 0.01 \% \text { methylene blue was } \\
\text { applied to all lesions after } 5 \mathrm{~min} \text { (pre- } \\
\text { irradiation time), } 100 \mathrm{~mW}, 32.14 \mathrm{~J} / \mathrm{cm}^{2}, 9 \mathrm{~J} \\
\text { and } 9 \mathrm{~s} \text { per point and PBMT } 100 \mathrm{~mW}, 17.8 \mathrm{~J} \\
/ \mathrm{cm}^{2}, 1 \mathrm{~J} \text { and } 10 \mathrm{~s} \text { of irradiation per spot at } \\
660 \text { and } 808 \mathrm{~nm} \text {, using a laser device } \\
\text { programming tool that changes the } \\
\text { wavelength periodically (every } 5 \text { seconds) }\end{array}$ & Wound healing in 4 days. \\
\hline Baeder et. al., 2021 & $\begin{array}{l}\text { Region between attached gingiva } \\
\text { and palate. Ulcers, erythema and } \\
\text { vesicles. }\end{array}$ & PBMT. 3J every 2 days for 1 week, $660 \mathrm{~nm}$. & $\begin{array}{l}\text { Burning ceased in } 7 \text { days } \\
\text { and after } 14 \text { days, the } \\
\text { lesions disappeared } \\
\text { completely. }\end{array}$ \\
\hline Garcez et. al., 2021 & $\begin{array}{l}\text { Upper and lower lips and inner } \\
\text { labial mucosa of the gingiva. } \\
\text { Edema with mucosal } \\
\text { desquamation, ulceration and } \\
\text { blood crusts on the inner surface of } \\
\text { the labial mucosa, gingival } \\
\text { petechiae and } \\
\text { erythematous/pseudomembranous } \\
\text { lesions on the dorsum of the } \\
\text { tongue, suggestive of candidiasis. }\end{array}$ & $\begin{array}{l}\text { PBMT and aPDT. aPDT was performed } \\
\text { using a low power laser and methylene blue } \\
\text { as a photosensitizer. } 300 \mu \mathrm{M} \text { aqueous } \\
\text { methylene blue solution was applied to the } \\
\text { lips, palate and tongue with a cotton swab for } \\
1 \text { min, followed by irradiation of a laser light } \\
\text { source operating at } 100 \mathrm{~mW} \text { and } 660 \mathrm{~nm} \text { with } \\
\text { the following protocol: } 90 \mathrm{sec} \text {, resulting in an } \\
\text { energy of } 9 \mathrm{~J} \text { per irradiation point and an } \\
\text { energy density of } 300 \mathrm{~J} / \mathrm{cm}^{2} \text {, total of } 6 \text { points } \\
\text { - including lips ( } 4 \text { points), palate ( } 2 \text { points) } \\
\text { and tongue ( } 4 \text { points), the total irradiation } \\
\text { time was } 15 \text { min. After the aPDT sessions, } \\
\text { oral lesions were irradiated with } 2 \mathrm{~J} \text { of energy } \\
\text { per point to cover the oral mucosa surface } \\
\text { bilaterally ( } 5 \text { points on each side) using the } \\
\text { same equipment, resulting in } 20 \text { seconds of } \\
\text { irradiation per point and energy density per } \\
\text { stitch of } 66 \mathrm{~J} / \mathrm{cm}^{2}\end{array}$ & $\begin{array}{l}\text { Oral lesions improved } \\
\text { after } 3 \text { days of aPDT } \\
\text { after which treatment } \\
\text { was followed with PBM } \\
\text { for } 4 \text { days. The patient } \\
\text { did not complain of } \\
\text { discomfort in the tongue } \\
\text { and lips after starting the } \\
\text { photodynamic treatment } \\
\text { with an antimicrobial. }\end{array}$ \\
\hline
\end{tabular}

Table 2- Characteristics of the included studies, according to Author and year of publication; Place and type of injury, Technique and Parameters in the use of Laser and outcome.

\section{The risk of bias assessment was established using the Joanna Briggs Institute (JBI)}

\section{Critical Assessment List for case series, and the articles analyzed here had a low risk of bias,} between $20-40 \%$ (Table 3).

Table 3 - Risk of bias assessed by the Joanna Briggs Institute Critical Appraisal Checklist for Case Series.

\begin{tabular}{|c|c|c|c|c|c|c|c|c|c|c|c|}
\hline Authors & Q.1 & Q.2 & Q.3 & Q.4 & Q.5 & Q.6 & Q.7 & Q.8 & Q.9 & Q.10 & $\%$ yes / risk \\
\hline Baeder et al., (2021) & $\mathrm{U}$ & $\sqrt{ }$ & $\sqrt{ }$ & $\sqrt{ }$ & $\sqrt{ }$ & $\sqrt{ }$ & & $\sqrt{ }$ & - & N/A & $70 \% / \mathbf{3 0 \%}$ \\
\hline Brandão et al., (2021) & $\mathrm{U}$ & $\sqrt{ }$ & $\sqrt{ }$ & $\sqrt{ }$ & $\sqrt{ }$ & $\sqrt{ }$ & & $\sqrt{ }$ & - & N/A & $70 \% / \mathbf{3 0} \%$ \\
\hline Ramires et al., (2021) & $\sqrt{ }$ & $\sqrt{ }$ & $\sqrt{ }$ & N/A & N/A & $\sqrt{ }$ & & $\sqrt{ }$ & - & N/A & $60 \% / 40 \%$ \\
\hline Teixeira et al., (2021) & $\sqrt{ }$ & $\sqrt{ }$ & $\sqrt{ }$ & $\sqrt{ }$ & $\sqrt{ }$ & $\sqrt{ }$ & & $\sqrt{ }$ & - & N/A & $80 \% / 20 \%$ \\
\hline Garcez et al., (2021) & $\sqrt{ }$ & $\sqrt{ }$ & $\sqrt{ }$ & N/A & $\sqrt{ }$ & $\sqrt{ }$ & & $\sqrt{ }$ & - & N/A & $70 \% / \mathbf{3 0} \%$ \\
\hline
\end{tabular}

$\sqrt{ }$ - yes; -- - No; U- Unclear; N/A - Not applicable. 


\subsection{Photosensitizer and Light Sources}

Brandão et al $(2021)^{21}$, after not observing improvement in vesicular, erythematous and vesicle lesions with the use of antiviral therapy with intravenous Acyclovir (250mg), 3 times a day for 7 days, used PBMT (Twin Flex, MMOptics, São Carlos , Brazil) with the therapeutic protocol for oral mucositis associated with cancer therapy, in patients with COVID-19, where the laser device was positioned perpendicular to the surface of the oral ulcers, for 10 seconds per site, operating at a wavelength of $660 \mathrm{~nm}, 40 \mathrm{~mW}$ average power, $0.04 \mathrm{~cm}^{2}$ beam area, $1 \mathrm{~W} / \mathrm{cm}^{2}$ irradiance, $0.4 \mathrm{~J}$ energy and $10 \mathrm{~J} / \mathrm{cm}^{2}$ creep.

Baeder et al $(2021)^{22}$ proposed the treatment of herpetic lesions that did not spontaneously regress in patients infected with COVID-19 through the use of PBMT with a wavelength of $660 \mathrm{~nm}$, with a dose of $3 \mathrm{~J}$ every $48 \mathrm{~h}$, in addition to the mouthwash with $0.12 \%$ chlorhexidine twice daily for 7 days.

Teixeira et al. (2021) ${ }^{23}$ and Ramires et al (2021) ${ }^{24}$ used similar protocols, the first one using an association of aPDT and PBMT for two days. For PBMT, a DUOß Laser device (MMOptics, São Carlos, SP, Brazil) was used at $660 \mathrm{~nm}$, contact mode, point to point, with $100 \mathrm{~mW}, 33 \mathrm{~J} / \mathrm{cm}^{2}, 0.5 \mathrm{~J}$ and $5 \mathrm{~s}$ per point. A total of 6 points were distributed for necrotic lesions, bleeding ulcers and erythematous lesions in patients with COVID-19. Soon after, an aPDT technique was performed, with $0.01 \%$ methylene blue applied to all lesions, and after $3 \mathrm{~min}$ (pre-irradiation time), the same laser parameters were used, but providing $40 \mathrm{~s}$ (4 J) for injury. Ramires differed in the pre-irradiation time, which waited $5 \mathrm{~min}$, and the laser device used was the Therapy EC® (DMC, São Carlos, SP, Brazil) at $660 \mathrm{~nm}$, contact mode, point to point, with $100 \mathrm{~mW}, 32.14 \mathrm{~J} / \mathrm{cm}^{2}, 9 \mathrm{~J}$ and $9 \mathrm{~s}$ per stitch. In this case, a total of 30 points were distributed over the affected areas: 20 points on the upper lip and 10 on the lower lip. In addition, on the second day, a PBMT session was held. The same areas described above were irradiated with the same equipment, but using $100 \mathrm{~mW}, 17.8 \mathrm{~J} / \mathrm{cm}^{2}, 1 \mathrm{~J}$ and $10 \mathrm{~s}$ of irradiation per point at 660 and $808 \mathrm{~nm}$, using a programming tool that triggers the two lengths simultaneously (every $5 \mathrm{sec}$ ).

Garcez et al. (2021) ${ }^{25}$ used a protocol of 03 sessions of aPDT (660nm diode laser + methylene blue) on the lips and tongue, every 24 hours to control contamination, followed by PBMT (low power laser, $100 \mathrm{~mW}, 2 \mathrm{~J} /$ point) for the lips, tongue and oral mucosa for four additional sessions every 24 hours, in ulcerative lesions, hemorrhagic crusts, petechiae and erythematous lesions in patients with COVID-19. 


\subsection{Synthesis of Meta-analysis}

The synthesis of statistical data was performed through meta-analysis, which consists of the statistical combination of results from two or more separate studies. Potential advantages of meta-analysis include an improvement in accuracy, the ability to answer questions not posed by individual studies, and the opportunity to resolve disputes arising from conflicting claims. Meta-analysis was performed on groups of studies that were homogeneous in terms of similarity in population, interventions, and outcomes to provide a meaningful summary. Most of the scientific articles selected in this study presented a low risk of bias and corroborated the final production of the analysis.

It should be noted that the results of the 11 clinical cases referring to the 5 articles of the study were evaluated through meta-analysis, considering that these studies presented homogeneous data quantitatively evaluating the use of PBMT and APDT for the reduction of oral lesions in patients affected by COVID-19.

\subsubsection{Repair of Oral Lesion by PBMT and aPDT/PBMT}

The results show favoring the associated use of PBMT with aPDT $(p=0.004)$, considering that there was a greater reduction in ulcerative, erythematous, necrotic and petechiae oral lesions in these patients positive by Covid-19, which is demonstrated in the "Forest plot" confidence interval (Tab.4). The fixed model was applied in this meta-analysis and heterogeneity is not a considerable factor for the analysis.

Heterogeneity was analyzed through the analysis of the approximate guide for interpretation in the context of meta-analysis of randomized clinical trials, which is made available by the Cochrane Group of Statistical Methods, ${ }^{30}$ according to the source of the Review Manager 5.4.1 program; as described below:

- $0 \%$ to $40 \%$ : may not be important;

- $30 \%$ to $60 \%$ : may represent moderate heterogeneity;

- $50 \%$ to $90 \%$ : may represent substantial heterogeneity;

- $75 \%$ to $100 \%$ : considerable heterogeneity.

Table 4: Forest plot demonstrating meta-analysis for oral manifestations for Covid-19 patients facing the treatment of PBMT associated with aPDT: 


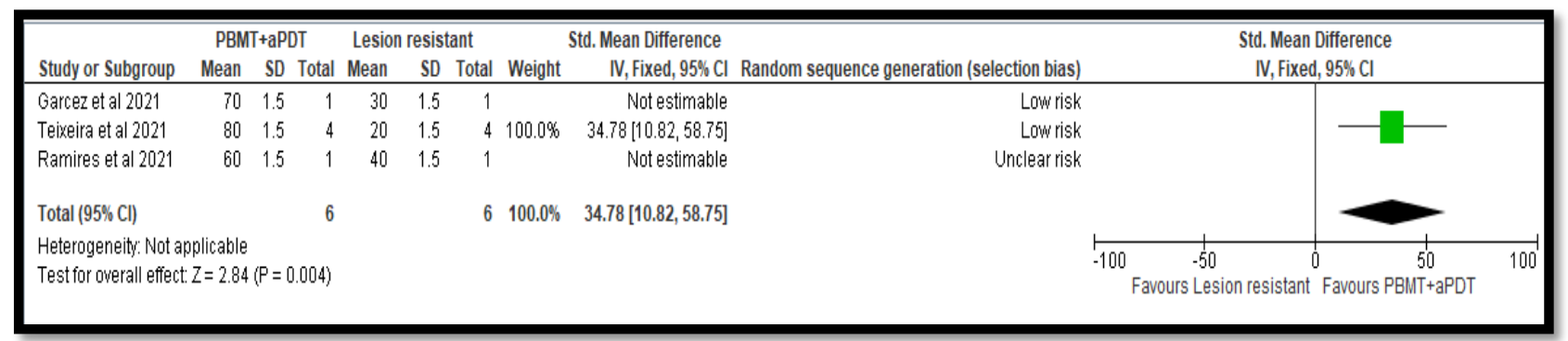

The isolated use of PBMT, according to the meta-analysis, was also effective in the treatment of oral lesions caused by Covid-19, with the result of a significant " $p=0.005$ " and a good confidence interval $(7.18,39.20)$.

Table 5: Forest plot demonstrating meta-analysis for oral manifestations for Covid-19 patients facing PBMT treatment:

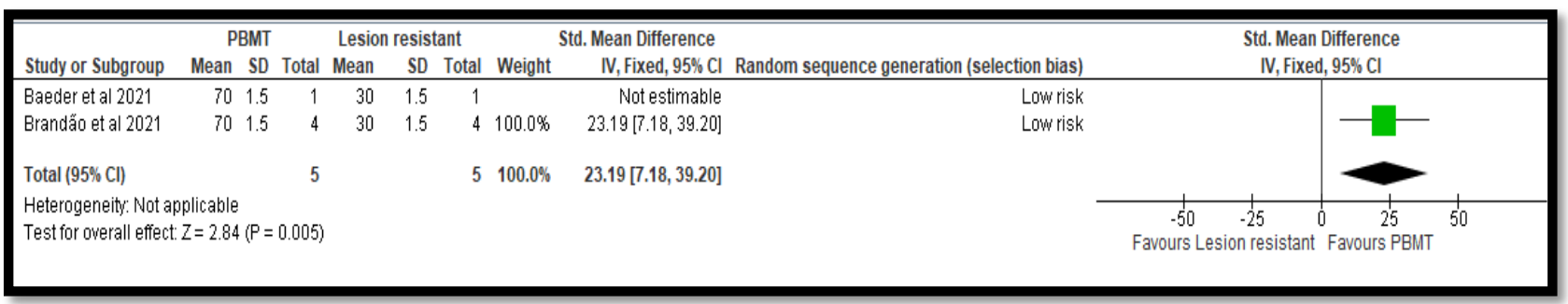

\subsection{Analysis of the main results}

PBMT without association with other laser therapy, ${ }^{21,22}$ the relief of painful symptoms occurred between 2 to 14 days with total healing of the lesion, excluding one case (Case 2), ${ }^{21}$ where until the date of publication of the article there was no response to laser therapy or regression of the COVID-19 infection picture.

PBMT associated with aPDT showed the best results with relief of painful symptoms in the first 24 hours and healing of the lesion within 4 days. ${ }^{23,24,25}$

Cases where laser therapy was not used as adjuvant, were young patients, mean age of 38.2 years and the lesions had their spontaneous regression within a considerable time, between 4 to 16 days.

\subsection{Effects of PBMT and aPDT on Sars-Cov-2 Contaminated Oral Tissues}

PBMT allowed relief of painful symptoms and complete resolution of lesions in the clinical cases presented in this review. When associated with aPDT, this improvement occurred in a shorter time span, thus suggesting that it is an effective therapy to treat oral lesions in patients affected by COVID-19. 


\section{DISCUSSION}

The pandemic process related to Covid-19 in the last two years, current studies related to morbid changes in the oropharyngeal region are in the process of evolution, as therapies for the repair of secondary lesions promoted by Sars-Cov-2 are ongoing. In an incipient way in the health-disease process, as well as the impossibility of clinicians and patients to evaluate a reduced amount of case studies or long-term research.

In this view, systematic reviews aim to ensure that clinical decisions are made with an up-to-date and complete understanding of the relevant scientific evidence. By judiciously evaluating the scientific literature, systematic reviews provide an up-to-date, qualitative summary of the state of research knowledge about an intervention, address the main research problem, namely, that of bias; as well as direct new research projects, indicating specific gaps in knowledge or whether evidence is lacking. ${ }^{31}$

The present study verified in the available scientific literature whether there was evidence regarding the efficacy and safety of the clinical applicability of PBMT and aPDT as effective options to treat oral manifestations of patients infected by Covid-19. The studies included in this research evaluated 5 scientific articles, where 11 clinical cases had similar interventions. All clinical cases evaluated in this systematic review demonstrated positive therapeutic effects that promoted a global impact on patients' health.

The focus of the systematic review was to address the use of PBMT, and/or aPDT/PBMT in the cytotoxic reduction of secondary manifestations promoted by Covid-19 that manifest themselves in the oral mucosa, through ulcers, erosions, aphthous lesions, plaques, hemorrhagic crusts among other alterations, being the tongue, labial mucosa and palate the most affected places. ${ }^{7}$

Lesions of the stomatognathic system that evolve negatively during the therapeutic process have a refractory potential to compromise and exacerbate immunosuppression, which adds to the appearance of opportunistic infections arising from atypical changes in oral mucosa cells, such as aphthous stomatitis, herpetic lesions and candidiasis.

It is extensive in the current literature that the main receptor for SARS-CoV-2 is ACE2, which would be closely linked to the imbalance of the oral microbiome that could induce an increase and sharp progression of the viral load in the oropharyngeal region with an eventual undesirable systemic repercussion..$^{10}$ 
Furthermore, PBMT and aPDT could become associative or complementary therapeutic strategies, as they present themselves as an auxiliary tool with a positive multi and interdisciplinary nature in the focal control of pathologies of the oropharyngeal tract, in addition to being a low-cost, painless and non-invasive technique. ${ }^{32} 33$ Furthermore, techniques related to Low Intensity Laser Therapy constitute, in the contemporary context, a form of treatment of painful symptoms and clinical picture of these diseases in the oral cavity by stimulating analgesic, anti-inflammatory and anti-edematous effects. ${ }^{13,14,15,16,17,18}$

This systematic review contributes to the amount of 11 clinical cases that used PBMT and/or aPDT as therapeutic resources for lesions in the oral cavity of patients affected by COVID-19, or awaiting natural regression of the lesions with topical medication, in some cases. ${ }^{21,22,23,24}$. The cases were patients admitted to public and private hospitals with symptoms characteristic of COVID-19 and confirmed through the rat-PCR ${ }^{26}$. Most were female (73\%), where 8 patients were aged over 60 years (average 75 years old) and 3 were younger than 60 years old (average 47 years old).

In the observational criterion for the incidental evaluation of oral lesions, in ascending order of nature of these manifestations, there was an involvement of ulcerative lesions, necrotic areas, herpetic lesions, erythematous and petechiae. Regarding the nature of the oral lesion, in ascending order: upper and lower lips, tongue, hard palate, buccal mucosa and attached gums, which is in agreement with the findings in the literature. ${ }^{6,7,8}$

Brandão and Baeder 21, 22 using protocols pertinent to the case, did not observe apparent regression of herpetic lesions on the lip, and used PBMT with clinical improvement of the lesions total tissue repair between 5 and 14 days. When they awaited spontaneous regression of the lesions, medications such as Acyclovir, mouthwash with $0.12 \%$ chlorhexidine, ascorbic acid, ${ }^{21,22}$ were used, in addition to individual medication protocols for each patient due to Covid-19 infection. ${ }^{27.28}$

Teixeira, Ramires and Garcez 23, 24, 25 implemented associative protocols between the PBMT and aPDT techniques, and observed relief of painful symptoms in the first 24 hours and healing of the lesion within 4 days, in accordance with the findings of Maya (2020) for the treatment of palatal ulcers. ${ }^{29}$

In the observational evaluation criteria of the 5 articles in question, it is important to emphasize that oral lesions appeared in these patients positive by Covid-19, concomitantly 
with loss of taste and smell, worsening of Covid-19 symptoms and were more severe in people older and systemically compromised.

Another considerable score is that these lesions were characterized by necrotic ulcers and with great painful symptoms. In young patients, with mild Covid-19, they presented as aphthous ulcers.

The risks of bias were analyzed following the Joanna Briggs Institute's Critical Assessment Checklist for systematic reviews and research summaries, ${ }^{20}$ and was between $60-80 \%$ in the studies, that is, the closer to $100 \%$, the more reliable the model contextualizes the variability of the response data around the mean, and the risk of bias between $20-40 \%$ and the lower this risk, the greater the methodological quality.

And it is worth noting the inclusion of the meta-analysis in this systematic review that highlights the intervention with PBMT and aPDT/PBMT with evidence of efficacy corresponding to the 5 studies included, as well as the action of the therapeutic theme in the reduction of secondary lesions in the oropharyngeal region caused by Covid-19, who showed a statistically significant improvement in tissue repair and consequent quality of life.

Therefore, a total of 11 cases were presented here, in this way, we can suggest that PBMT and aPDT are effective therapies, both isolated, but mainly when associated, as they are relatively low-cost therapies, of practical employability in hospital or outpatient settings, and that they proved to be effective in repairing the clinical picture of oral lesions of different nature and locations, in these patients affected by COVID-19 in a short period of time. However, as it is a recent disease on the world stage and non-random publications, it is necessary that further research on the benefits and harms of the use of low-intensity laser is carried out so that it is really effective in reducing and neutralization of diseases of the oropharyngeal tract in detriment of the probable high viral load of Sars-Cov-2, for example, investigating the immunoexpression of ACE2 in oral lesions or saliva, and evaluating the possibility of these therapies inhibiting or altering this receptor at these sites. Also, the description of cases with specific protocols for each lesion in order to enrich our findings in these patients.

\section{CONCLUSION}


Based on the findings of this systematic review and literature meta-analysis, PBMT and aPDT were effective in the treatment of oral lesions in patients infected with COVID-19 in a short period of time.

The simultaneous use of PBMT/aPDT techniques, with different wavelengths, and the use of the photosensitive substance of methylene blue enhance the decontamination action of the oral cavity with eventual repair of the affected cells.

\section{FUNDING}

None.

\section{DISCLOSURE STATEMENT}

The authors report no conflicts of interest. The authors alone are responsible for the content and writing of the manuscript.

\section{REFERENCES}

1. Shibo $\mathrm{J}$ et al. A distinct name is needed for the new coronavirus. The Lancet, Volume 395, Issue 10228, 949, 2020

2. Ferguson NM, Laydon D, Nedjadi-Gilani G, et al. Report 9: impact of nonpharmaceutical interventions (INP) in reducing mortality from COVID19 and demand for health care. Imperial College COVID-19 Response Team. https://www.imperial.ac.uk/mrc-global-infectious-disease-analysis/covid-19/report-9impact-of-npis-on-covid-19/ .

3. Chaolin $\mathrm{CH}$ et al. Clinical Characteristics of Patients Infected with New Coronavirus 2019 in Wuhan, The Lancet, Volume 395, Issue 10223, 497-506

4. Berlin DA, Gulick RM, Martinez FJ. Severe Covid-19. N Engl J Med. 2020 Dec 17;383(25):2451-2460. doi: 10.1056/NEJMcp2009575. Epub 2020 May 15. PMID: 32412710.

5. Huang C, Wang Y, Li X, et al. Clinical features of patients infected with 2019 novel coronavirus in Wuhan, China. Lancet. 2020;395(10223):497-506. https://doi.org/10.1016/S0140-6736(20)30183-5 
6. Soares CD, Carvalho RA, Carvalho KA, Carvalho MG, Almeida OP. Oral lesions in a patient with COVID- 19. Med Oral Patol Oral Cir Bucal. 2020;25(4):e563- e564. https://doi.org/10.4317/medoral.24044

7. Iranmanesh B, Khalili M, Amiri R, Zartab H, Aflatoonian M. (2021). Oral manifestations of COVID-19 disease: a review article. Dermatological therapy. 202134 (1),14578. https://doi.org/10.1111/dth.14578

8. Santos JA, Normando AGC, Sllva ACC etal. Oral Manifestations in Patients with COVID-19: A Living Systematic Review. Journal Dental of Research. Vol 100, Issue 2, 2021

9. Jia HP, Look DC, Shi L, et al. ACE2 receptor expression and severe acute respiratory syndrome coronavirus infection depend on differentiation of human airway epithelia. $J$ Virol. 2005;79:14614- 14621

10. Zhong, Mei et al. "ACE2 and furin expressions in oral epithelial cells possibly facilitate COVID-19 infection by respiratory and fecal-oral tracts." Borders in Medicine vol. 7 580796. December 10, 2020, doi: 10.3389 / fmed.2020.580796

11. Pacheco JA. Low level laser therapy contributes to the prevention of mucositis and immunity against Sars-CoV-2. Case Rep Rev Open Access. 2020;1(2):111.

12. Spanemberg JC, Figueiredo MA, Cherubini K, Salum FG. Low-level laser therapy: a review of its applications in the treatment of oral mucosal disorders. Altern Ther Health Med. Novembro de 2016; 22 (6): 24-31. PMID: 27866178.

13.Zecha JA, Raber-Durlacher JE, Nair RG, Epstein JB, Elad S, Hamblin MR, Barasch A, Migliorati CA, Milstein DM, Genot MT, Lansaat L. Low-level laser therapy/photobiomodulation in the management of side effects of chemoradiation therapy in head and neck cancer: part 2: proposed applications and treatment protocols. Supportive Care in Cancer. 2016 Jun;24(6):2793-805

14. Flowers FL. Photodynamic therapy in cariogenic microorganisms: an in vitro study.2012.152f. São Paulo State University-Faculty of Dentistry of Araraquara,2012.

15. Issa MCA, Manela-Azulay M. (2010). Photodynamic therapy: a literature review and image documentation. Brazilian Annals of Dermatology, 85 (4), 501-511. https://dx.doi.org/10.1590/S0365-05962010000400011

16. Castano A.P. Mechanisms in photodynamic therapy: part two-cellular signaling, cell metabolism and modes of cell death. Photodiagn Photodyn Ther. 2005;2(1):1-23.

17. Wiehe A. Trends and targets in antiviral phototherapy. Photochem. Photobiol. Sci. 2019;18(11):2565-2612. 
18. Monjo A.L.A. Photodynamic inactivation of herpes simplex viruses. Viruses. 2018;10(10):1-16. doi: 10.3390/v10100532.

19. Moher, D, Shamseer, L, Clarke, M, Ghersi, D, Liberati, A, Petticrew, M, Shekelle, P, Stewart, LA; PRISMA-P Group . 2015. Preferred Reporting Items for Systematic Review and Meta-analysis Protocols (PRISMA-P) 2015 statement. Syst Rev. 4(1):1.

20. Moola S, Munn Z, Tufanaru C, Aromataris E, Sears K, Sfetcu R, Currie M, Qureshi R, Mattis P, Lisy K, Mu P-F. Chapter 7: Systematic reviews of etiology and risk. In: Aromataris E, Munn Z (Editors). Joanna Briggs Institute Reviewer's Manual. The Joanna Briggs Institute, 2017. Available from https://reviewersmanual.joannabriggs.org/

21. Brandão TB, Gueiros LA, Melo TS, et al. Oral lesions in patients with SARS-CoV-2 infection: could the oral cavity be a target organ?. Oral Surg Oral Med Oral Pathol Oral Radiol. 2021;131(2):e45-e51.

22. Baeder FM, Albuquerque ACL, Corazza PFL et al. Oral lesions in patients infected with SARS-CoV-2: a case series. Research, Society and Development 2021, v. 10, n. 4, p. e45410414349.

23. Teixeira IS, Leal FS, Tateno RY, Palma LF, Campos L. Photobiomodulation therapy and antimicrobial photodynamic therapy for orofacial lesions in patients with COVID19: A case series [published online ahead of print, 2021 Apr 1]. Photodiagnosis Photodyn Ther. 2021;34:102281.

24. Ramires MCCH, Mattia MB, Tateno RY, Palma LF, Campos L. A combination of phototherapy modalities for extensive lip lesions in a patient with SARS-CoV-2 infection. Photodiagnosis Photodyn Ther. 2021.

25. Aguinaldo S. Garcez, Maria Goretti T. Delgado, Marcelo Sperandio, Felipe T. Dantas e Silva, Josilene S. Rita de Assis and Selly S. Suzuki. Photobiomodulation, Photomedicine and Laser Surgery. doi:10.1089/photob.2020.4977

26. Corman, Victor M et al. "Detection of 2019 novel coronavirus (2019-nCoV) by realtime RT-PCR." Euro surveillance: bulletin Europeen sur les maladies transmissibles = European communicable disease bulletin vol. 25, 3 (2020): 2000045.

27. Lotfi, Melika et al. "COVID-19: Transmission, prevention, and potential therapeutic opportunities." Clinica chimica acta; international journal of clinical chemistry vol. 508 (2020): 254-266. doi:10.1016/j.cca.2020.05.044 
28. Carlotti APCP et al. "COVID-19 Diagnostic and Management Protocol for Pediatric Patients." Clinics (Sao Paulo, Brazil) vol. 75 e1894. 17 Apr. 2020, doi:10.6061/clinics/2020/e1894

29. Maya R, Ladeira LLC, Maya JEP, Mail LMG, Bussadori SK, Paschoal MAB. The Combination of Antimicrobial Photodynamic Therapy and Photobiomodulation Therapy for the Treatment of Palatal Ulcers: A Case Report. J Lasers Med Sci. 2020 Spring;11(2):228-233. doi: 10.34172/jms.2020.38. Epub 2020 Mar 15. PMID: 32273968; PMCID: PMC7118493.

30. Higgins JPT, Thomas J, Chandler J, Cumpston M, Li T, Page MJ, Welch VA (2019) Cochrane Handbook for Systematic Reviews of Interventions version 6.0 (updated July 2019). Cochrane, 2019. Available from www.training.cochrane.org/handbook.

31. Chalmers I, Bracken MB, Djulbegovic B, Garattini S, Grant J, Gulmezoglu AM, Howells DW, loannidis JP, Oliver S (2014)How to increase value and reduce waste when research priorities are set. Lancet 383: 156-165.

32. 32. Hamblin $\mathrm{M}$ et al. "Photobiomodulation and the brain: a new paradigm." Journal of optics (2010) vol. 19.1 (2017): 013003. doi: 10.1088 / 2040-8986 / 1/19/013003

33. Hamblin M, Huang YY, Photobiomodulation in the Brain, Low-Level Laser (Light) Therapy in Neurology and Neuroscience, 1st Edition, Paperback ISBN: 9780128153055, ISBN: 9780128153062, July 2019 